\title{
Physical activity in elderly
}

Jan Cvecka (1,2), Veronika Tirpakova (1,2), Milan Sedliak (1,2), Helmut Kern (3,4), Winfried Mayr (5), Dušan Hamar (1)

(1) Comenius University Bratislava, Slovakia, Faculty of Physical Education and Sport; (2) Aging and Lifestyle Diseases Research Centrum, Comenius University Bratislava, Slovakia; (3) Institute of Physical Medicine and Rehabilitation,Wilhelminenspital, Vienna, Austria; (4) Ludwig Boltzmann Institute of Electrical Stimulation and Physical Rehabilitation, Vienna, Austria;(5) Center of Medical Physics and Biomedical Engineering, Medical University of Vienna, Vienna, Austria

\begin{abstract}
Aging is a multifactorial irreversible process associated with significant decline in muscle mass and neuromuscular functions. One of the most efficient methods to counteract age-related changes in muscle mass and function is physical exercise. An alternative effective intervention to improve muscle structure and performance is electrical stimulation. In the present work we present the positive effects of physical activity in elderly and a study where the effects of a 8week period of functional electrical stimulation and strength training with proprioceptive stimulation in elderly are compared.
\end{abstract}

Key Words: older age, physical activity, sarcopenia, electrical stimulation, proprioceptive stimulation

Eur J Transl Myol - Basic Appl Myol 2015; 25 (4): 249-252

The world population is getting older and the percentage of elderly people is continually increasing. In 2010 the percentage of elderly persons above 65 years was approximately $8 \%$ of the global population. The projection for 2050 is approximately $16 \%$, which will present around 1.5 billion people. ${ }^{1}$ It is well known, that aging causes gradual changes in the organism, which leads to loss of function, weakness, disease and death. ${ }^{2}$ There is also evidence that older people are among the most sedentary and physically inactive segment of societ. ${ }^{2}$ Focusing at the aged muscles, we know that there is a loss of muscles mass of $0.5 \%-1 \%$ per year resulting in a decrease of strength $^{3}$ and decline of rapid force production, so crucial for preventing falls in elderly. ${ }^{3}$

All these negative changes lead to many problems of performing daily activities. For example, around $42 \%$ of elderly Americans have difficulties walking two to three blocks or transferring from the chair. ${ }^{4}$ They are reported to have problems regarding their slow gait when crossing the street before the traffic light changes. ${ }^{5}$ Another group of consequences are falls. Statistics show that $30 \%$ of seniors (over 65 years) fall at least once per year and in the older group (over 80 years and elderly in nursing houses) the number is increased up to $50 \% .^{6-8}$ The average duration of a hospitalization is between $5-20$ days with costs over
Euros $3000 .{ }^{9}$ The prediction for the future is that the number of falls will double by $2030 .{ }^{10}$

Therefore one of the main questions regarding elderly is: can we stop the negative changes in the body? No, we cannot stop it, but we can counteract or slow down the decrease of physical fitness and functional capacity. We know that, together with proper and balanced nutrition, physical activity represents the most effective way to counteract the decline of functional capacity related to aging. ${ }^{11}$

The World Health Organization (WHO) published guidelines on the importance of physical activity in elderly people. ${ }^{11}$ According to these guidelines, exercise is an efficient and cost-effective way of preventing the decline of older people's functional capacity. Physical activity can help in preventing and managing certain chronic diseases and conditions. Strength, balance and flexibility exercises are the most effective strategies to prevent falls among older adults. The positive effects of physical activity are longer independency in self-care activities, higher self-esteem, better quality of life, higher life expectancy, and decreased mortality. Also $42 \%$ decrease of risk of falling is another positive effect for older people.

Other guidelines with the description of type and amount of physical activity were published by WHO and other organizations. ${ }^{12}$ Today we know that some 
Physical activity in elderly

Eur J Transl Myol - Basic Appl Myol 2015; 25 (4): 249-252

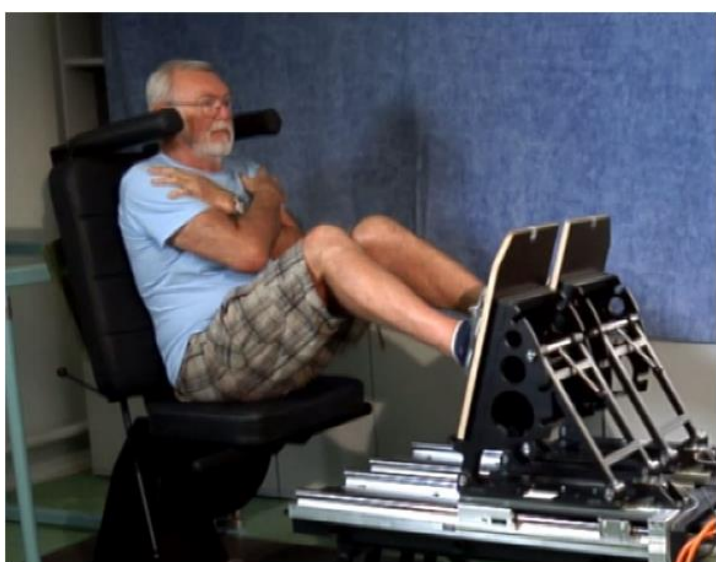

Fig 1. Computer controlled, linear motor powered leg press dynamometer.

activity is better than none and that it is never too late to start. This means that also elderly will benefit from activity even when they were inactive for the majority of their life. Important findings are that even the minimal recommended physical activity amount provides $30-50 \%$ of health benefits. ${ }^{13}$ More activity, up to a certain point (300 min/week), is better than shorter activity duration. Recommendations are 150 minutes of moderate-intensity physical activity in a week or 75 minutes, if vigorous-intensity is applied or an equivalent combination. ${ }^{12}$

The WHO recommendations don't divide training sessions during one week. There is no prescription in amount of training sessions but the minimal bout duration is 10 minutes. ${ }^{12}$ For additional health benefits 300 minutes of moderate training or 150 minutes of vigorous-intensity or an equivalent are required. WHO recommends resistance exercises 2 or more days per week targeting major muscle groups. Elderly with poor mobility should perform exercises to enhance balance and prevent falls on 3 or more days per week. Also, elderly with health limitations should be as physically active to the point their abilities and conditioning allow.

The American College of Sport Medicine (ACSM) together with the American Heart Association (AHA) published recommendations with some more detailed

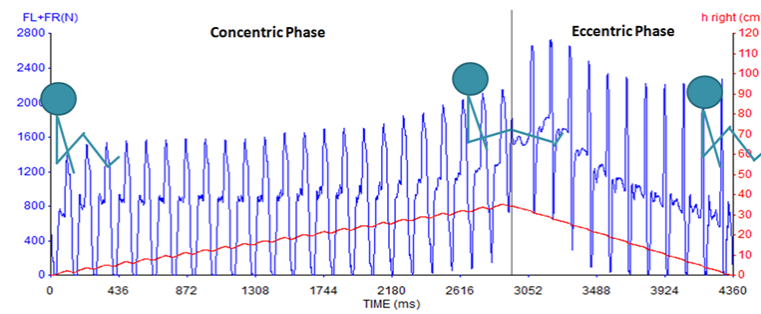

Fig 2 Force curve during a single repetition of proprioceptive stimulation mode

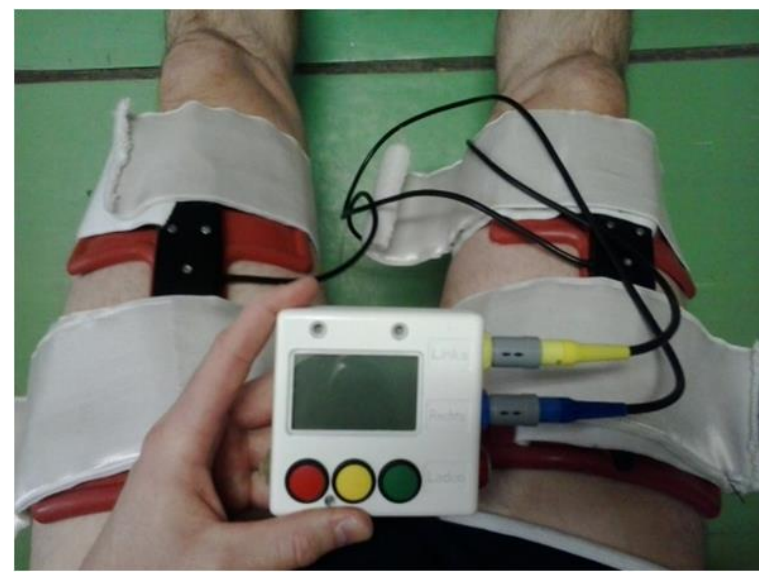

Fig. 3 Surface electrical stimulation: the processing unit and electrodes.

descriptions. For aerobic activities 30 minutes 5 times per week of moderate-intensity or 20 minutes 3 x week of vigorous-intensity or an equivalent combination with minimal bout duration of 10 minutes are recommended $^{14}$ Strength training should be included twice a week consisting of 8-10 exercises with 10-15 repetitions and 1-2 series. In Austria, the recommendations were published in 2010 by Gesundheit Österreich GmbH. ${ }^{15}$. These guidelines are inspired with both WHO and ACSM/AHA. According Austrian recommendations, 150 minutes of moderateintensity and per week and 75 minutes of vigorousintensity or an equivalent combination, 4 times a week with a minimum duration of 10 minutes each training session are recommended. Strength training is recommended twice a week on major muscle groups. Exercises to enhance balance and to prevent fall are recommended. However, there is no precise prescription for balance training within Austrian recommendations.

\section{Clinical study}

Beside the published recommendations scientist keep still looking for a more effective way of training in healthy and weak elderly. This was also the main

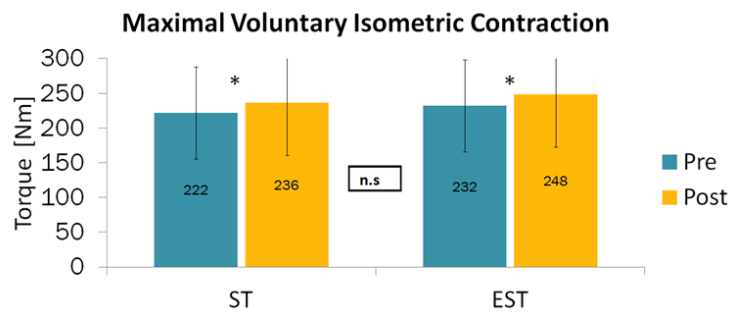

Fig 4 Change in peak torque during MVC following strength training (ST) and electrical (FES) stimulation. Statistical significance indicated by asterisks $(* p<0.05)$. 
Physical activity in elderly

Eur J Transl Myol - Basic Appl Myol 2015; 25 (4): 249-252

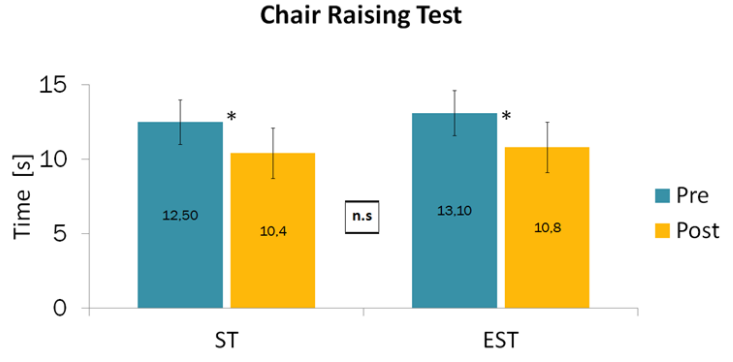

Fig 5. Change in sit-to-stand time following strength training (ST) and electrical stimulation (FES). Statistical significance indicated by asterisks $(* p<0.05)$

frequency of the force peaks of $16 \mathrm{~Hz}$ and $14 \mathrm{~Hz}$ in the concentric and eccentric phase respectively (Figure 2). The training session of the ST consisted of 5 sets with 12 - 14 second contraction time (first two weeks 4 sets of $8-10 \mathrm{sec}$.), performed with a maximal effort.

FES ( $n=14,70.2 \pm 3.26$ years) underwent transdermal surface electrical stimulation of both knee extensors muscles, using a custom build programmable voltagecontrolled stimulator, ${ }^{16}$ three times per week (Figure 3 ) with an additional load placed on ankles (1 to $2.5 \mathrm{~kg}$ ). One training session of the FES consisted of 3 sets of 10 minutes (first two weeks 3 sets of 6 minutes) of stimulation. The intervention period lasted 8 weeks in both groups.

Subjects were tested for lower extremity isometric muscle strength, habitual and maximal walking speed over $10 \mathrm{~m}$ and chair-rising test both before and after the intervention.

We observed that post-training maximum voluntary isometric contraction measured on training-non specific force chair increased after both training methods (Figure 4). Similar results were found in functional tests. Both groups improved in sit to stance performance (chair rising test) (Figure 5), maximal gait speed (Figure 6) and time up-and-go test (Figure 7). They both improved with no real significance between

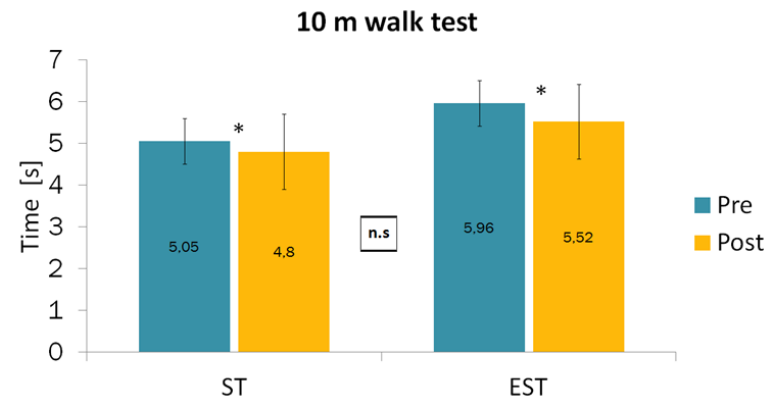

Fig 6. Time to completion in maximal walking speed test following strength training (ST) and electrical stimulation (FES). Statistical significance indicated by asterisks $(* p<0.05)$.

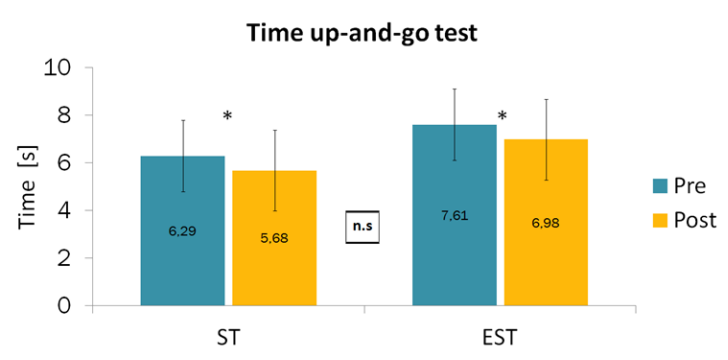

Fig 7. Time to completion in time up-and-go test following strength training (ST) and electrical stimulation (FES). Statistical significance indicated by asterisks $(* \mathrm{p}<0.05)$.

the groups. The only difference was in the postural stability test, in which only the leg press group increased significantly. ${ }^{17}$

\section{Conclusions}

In conclusion, we found that both strength training with proprioceptive stimulation and functional electrical stimulation similarly improve the maximal strength and motor function in elderly. Strength training seems to be more beneficial for postural control in elderly. Both methods represent an effective and safe way to improve strength and functional capabilities in sedentary elderly people.

\section{Acknowledgement}

This work was supported by European Regional Development Fund - Cross Border Cooperation Programme Slovakia - Austria 2007-2013 (InterregIVa), project Mobilität im Alter, MOBIL, N_00033 (partners: Ludwig Boltzmann Institute of Electrical Stimulation and Physical Rehabilitation, Austria, Center for Medical Physics and Biomedical Engineering, Medical University of Vienna, Austria, and Faculty of Physical Education and Sports, Comenius University in Bratislava, Slovakia); Austrian national co-financing of the Austrian Federal Ministry of Science and Research; Ludwig Boltzmann Society (Vienna, Austria).

This paper is from the talk presented to the Interreg IVa Final Meeting November 8 2014, Vienna, Austria.

\section{Corresponding Author}

Jan Cvecka, Faculty of Physical Education and Sports, Comenius University, Bratislava, Slovakia E-mail: cvecka@fsport.uniba.sk

\section{E-mail of coauthors}

Veronika Tirpakova:

veronika.tirpakova@fsport.uniba.sk

Milan Sedliak: milan.sedliak@fsport.uniba.sk

Helmut Kern: wil.pys.kern-forschung@wienkav.at Winfried Mayr: winfried.mayr@meduniwien.ac.at Dušan Hamar: hamar@fsport.uniba.sk 


\section{Physical activity in elderly}

Eur J Transl Myol - Basic Appl Myol 2015; 25 (4): 249-252

\section{References}

1. United Nations. World Population Prospects: The 2010 Revision. Available at: http://esa.un.org/unpd/wpp.

2. Paterson D, Warburton D. Physical activity and functional limitations in older adults: a systematic review related to Canada's Physical Activity Guidelines. I J Behav Nut Phys Act 2010; 7(38).

3. Mitchell WK, Williams J, Athertone P, et al. Sarcopenia, dynapenia, and the impact of advancing age on human skeletal muscle size and strength; a quantitative review. Frontiers in Physiology 2012;3:260-78.

4. Statistics FIFOA-R. Older Americans 2008: Key Indicators of Well-being; Washington, DC: U.S. Government Printing Office; 2008.

5. Hyatt RH, Whitelaw MN, Bhat A., Scott S, Maxwell JD. Association of muscle strength with functional status of elderly people. Age and Ageing 1990;19:330-6.

6. Blake AJ, Morgan K, Bendall MJ, Dallosso H. Falls by elderly people at home: prevalence and associated factors. Age Ageing 1988;17:365-72.

7. Tinetti ME. Factors associated with serious injury during falls by ambulatory nursing home residents. J Am Ger Soc 1987;35:644-8.

8. Izquirdo M, Aguado X, Gonzales R, Lopez JL, Hakkinen K. Maximal and explosive force production capacity and balance performance in men of different ages. Eur J Appl Physiol 1999;79: 260-7.

9. Nurmi I, Luthje P. Incidence and costs of falls and fall injuries among elderly in institutional care. Scand J Primary Health Care 2002; 20:11822.
10. Kannus P, Palvanen M, Niemi S, Parkkari J. Alarming rise in the number and incidence of fallinduced cervical spine injuries among older adults. J Ger: Biol Sci Med Sci 2007;62:180-3.

11. WHO. A guide for population-based approaches to increasing levels of physical activity: implementation of the WHO Global Strategy on Diet, Physical Activity and Health. Geneva, World Health Organization, 2007.

12. WHO. Global recommendations on physical activity for health. ISBN 9789241599979 . WHO. 2010.

13. Haskell WL. Health consequences of physical activity: understanding and challenges regarding dose-response. Med Sci Sports Exerc 1994;26:649-60.

14. Nelson ME, Rejeski W J, Blair SN, et al. Physical activity and public health in older adults: recommendation from the American College of Sports Medicine and the American Heart Association. Med Sci Sports Exerc 2007;39:143545.doi:10.1249/mss.0b013e3180616aa2.

15. Titze S, Ring-Dimitriou S, Schober $\mathrm{PH}$, et al. Österreichische für gesundheitswirksame Bewegung. Wien: Bundesministerium für Gesundheit, Gesundheit Österreich GmbH, Geschäftsbereich Fonds Gesundes Österreich (Hrsg.); 2010.

16. Krenn M, Haller M, Bijak M, Unger E, Hofer C, Kern H, Mayr W. Safe neuromuscular electrical stimulator designed for the elderly. Artif Organs 2011; 35:253-6.

17. Zampieri S, Pietrangelo L, Loefler S, et al. Lifelong physical exercise delays age-associated skeletal muscle decline. J Gerontol A Biol Sci Med Sci 2014 Feb 18. 